مدلسازى براكنش تون جشمدرشت (Thunnus obesus Lowe, 1839) در اقيانوس هند با استفاده از متغيرهاى محيطى حاصل از تصاوير ماهوارهاى تصاى

\author{
على حقى وايقان"
}

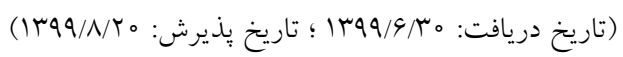

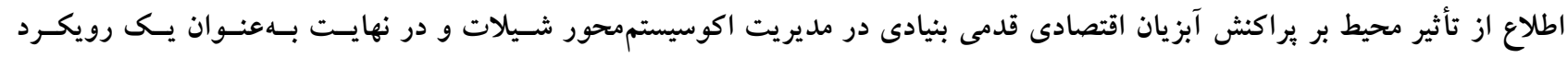

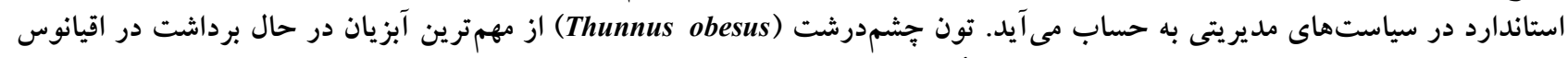

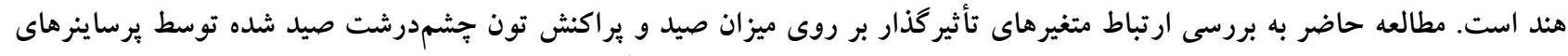

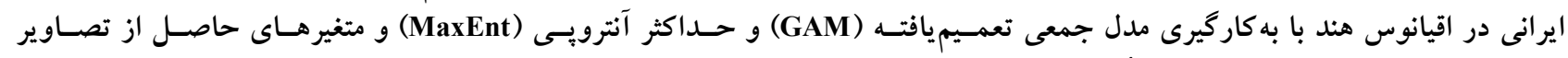

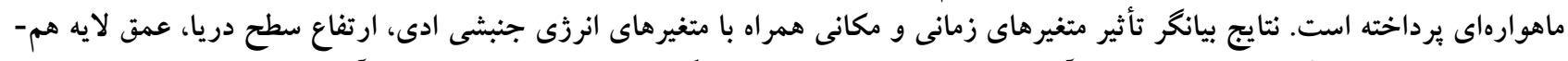

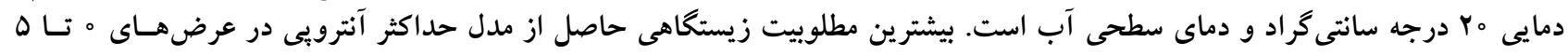

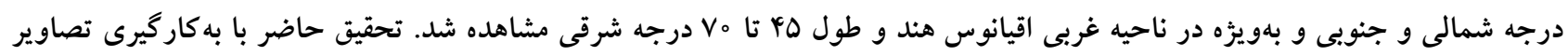

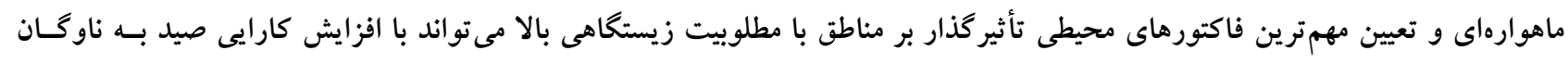

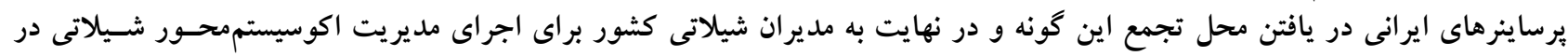

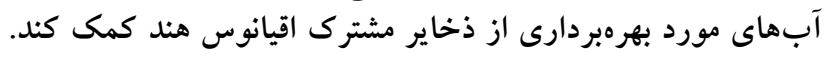

وازههاى كليدى: تون جشمدرشت، ير اكنش، مدلسازى زيستخاه، مديريت اكوسيستم 


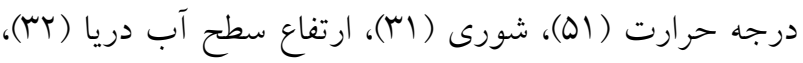

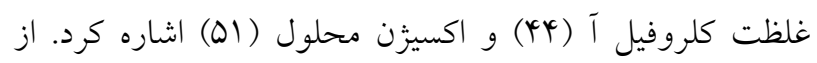
سوى ديخر مشخص شده تغيرات اقليم نيز اثرات مهمى در ابعاد مختلف از جمله محدوده يراكنش و تحليل كيفيت زيستخاه انواع سطحزيان درشت در مقياس جهانى دارد (T (T). مدلسازى زيستخاه امروزه از جمله كاربردى ترين ابزارها براى رسيدن به مديريت اكوسيستممحور شيلاتى و ه) $($ EBFM =Ecosystem Based Fishery Management $)$ (Y) معرفى شده و بلطور عمده در بسيارى از كونههاى

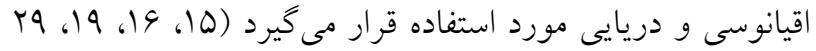
و مَr). اين رويكرد بهطور وسيع در مديريت و و ارزيابى كونهاى مهم اقتصادى، ارزيابىهاى بومشناسى و بازسازى

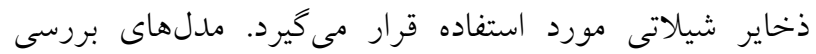

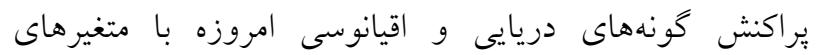
محيطى حاصل از تصاوير ماهوارهاى بهطور كسترداى در برائ سراسر جهان با اهداف مختلف در حال استفاده است (VV، 19،

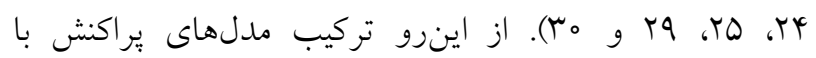
تصاوير ماهوارهاى مىتواند ضمن صرفهجويى در وقت و منابع

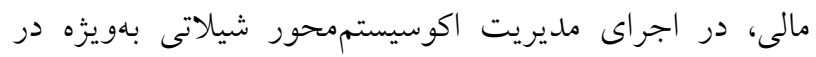
مورد تونماهيان داراى ارزش تجارى به مديران مان و و تصميم كيران

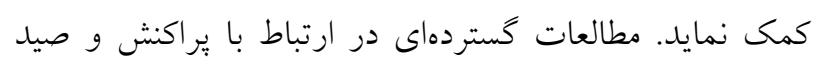

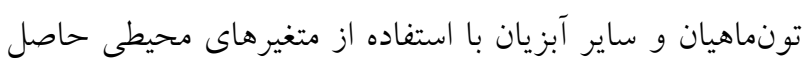

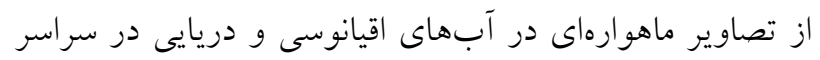

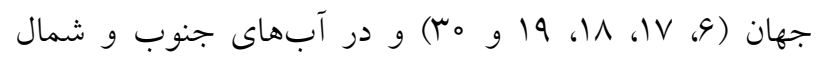

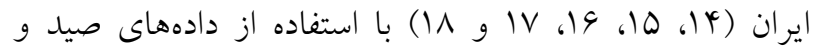

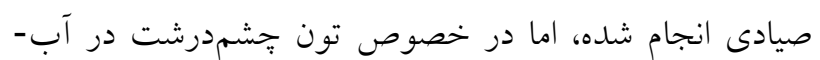
هاى جنوبى كشور مطالعهاى صورت نيذيرفته است. از اينرو، در اين مطالعه تلاش شده ارتباط بين صيد تون جشمدرشت بال متغيرهاى حاصل از تصاوير ماهوارهاى كه بهنوعى بيانكر تغييرات سطحى آب اقيانوسها هستند بررسى شود تا ضمن

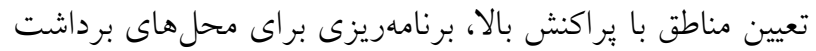

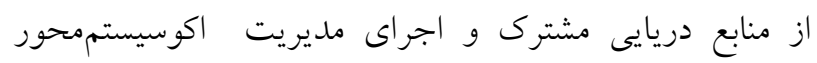

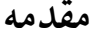

تونماهيان جزء تجارىترين گونههاى قابل استحصال در

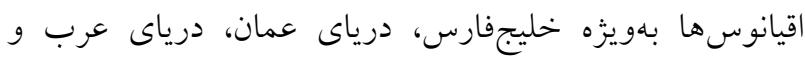

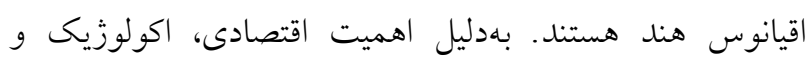

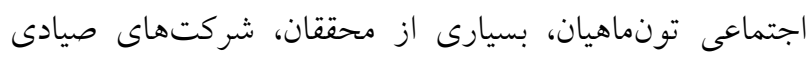

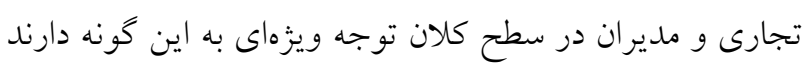

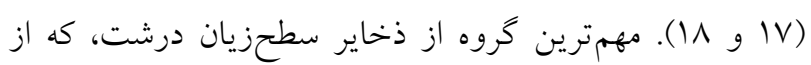

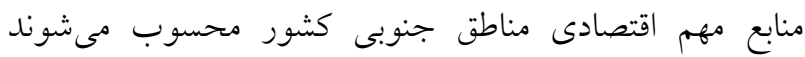
تونماهيان هستند كه نياز عمده كارخانجات كنسروسازى كشور

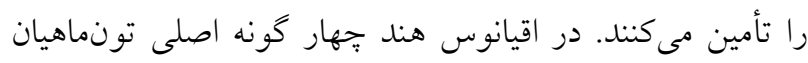

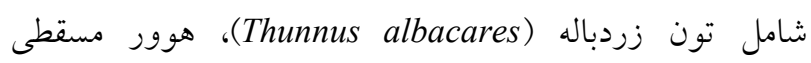
(Katsuwonus pelamis)، جشمدرشت (Thunnus obesus) و آلباكور (Thunnus alalunga) اهميت اقتصادى زيادى دارند كه در اين ميان، تون جشمدرشت بهسبب كيفيت كوشت آن ارزش

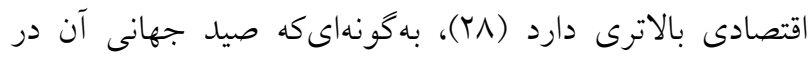

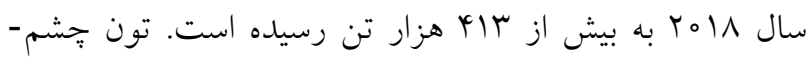

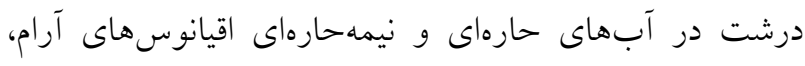
اطلس و هند يراكنش دارد (VV V VV). صيد تونماهيان در آبهاى جنوب كشور توسط دو بخش ماهيخيرى سنى و

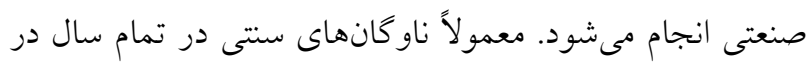
آبهاى سرزمينى خليج فارس و درياى عمان فعاليت مى كنند و

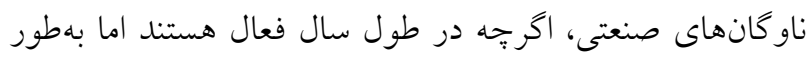

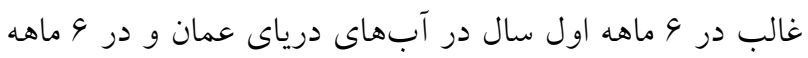

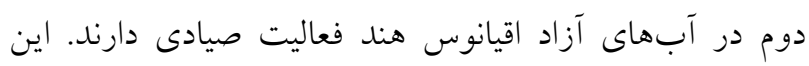

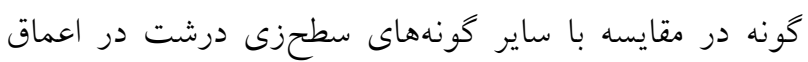

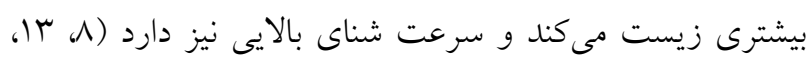

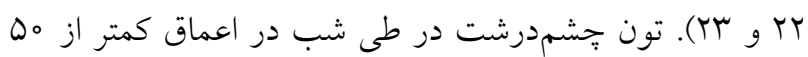
متر و در طول روز تا اعماق هم متر نيز حضور دارد كه اين

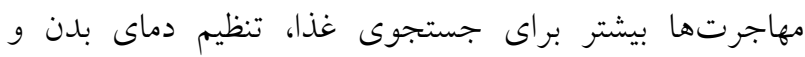

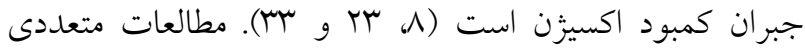

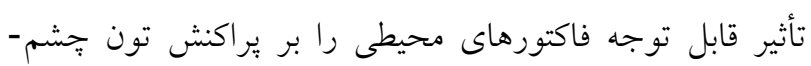
درشت مشخص نموده است. از جمله اين فاكتورها مىتوان به له ليه 


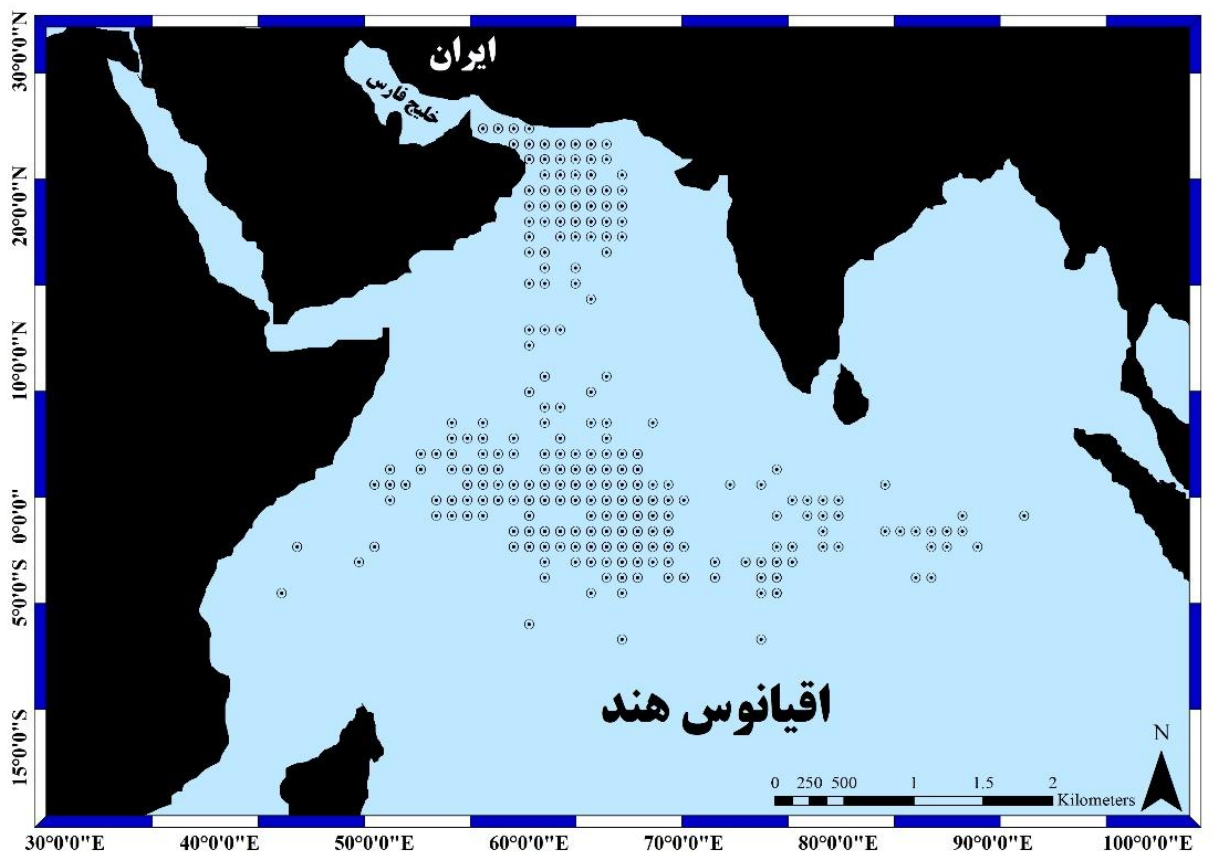

شكل ا. منطقه مورد مطالعه و موقعيت جغر افيايى مناطق تور ريزى برساينرهاى ايرانى در اقيانوس هند (رنخى در نسخه الكترونيكى)

(FAO =Food and Agricultural Organization) تونماهيان اقيانوس هند (ndian Ocean Tuna Commission)

$$
\text { (IOTC }
$$

در اين مطالعه متغيرهاى مورد بررسى به سه بخش

متغيرهاى زمانى (ماه و سال)، مكانى (طول و عرض جغر افيايى) و متغيرهاى محيطى تقسيم شد. در مجموع از V متغير محيطى قابل تهيه با استفاده از تصاوير ماهوارهاى كه بهطور رايج در يزوهشهاى اقيانوسشناسى شيلاتى و مدلسازى يراكنش

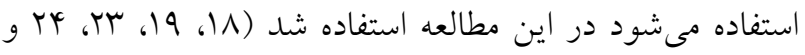
هب). اين متغيرهاى محيطى از سنجندههاى مختلف ازجمله

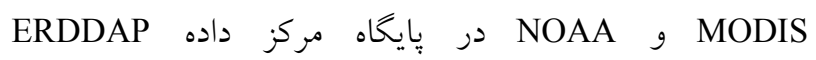
و (https://coastwatch.pfeg.noaa.gov/erddap/index.html)

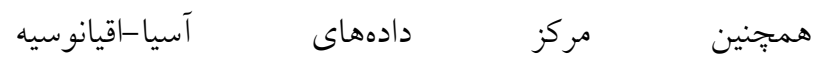
استخراج شد. در ادامه (http://www.apdrc.soest.hawaii.edu) دادههاى اخذشده با استفاده از برنامه MATLAB ) (Interactive Data Language; Version7.0) IDL و و (R2015a خوانده شده و مقادير عددى متغيرها استخراج شد. با توجه به متفاوتبودن دقت مكانى برخى متغيرها، همه آنها
شياتى بلصورت منطقهاى به مديران شيلاتى كشور

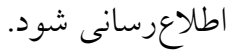

مواد و روش ها در مطالعه حاضر دادههاى صيد بِرساينرهاى ايرانى طى سالهاى

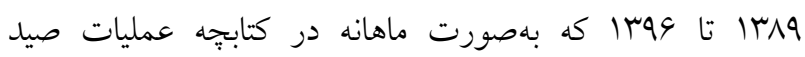
(Logbook) محدوده جغرافيايى صيد شناورهاى :برساينر در عرضهاى جغرافيايى بين ^ درجه جنوبى تا ها درجه شمالى و طول جغرافيايى اله تا سو درجه شرقى بوده است (شكل (). در مجموع تعداد الما موقعيت جغرافيايى توسط برساينرها ثبت شده كه در

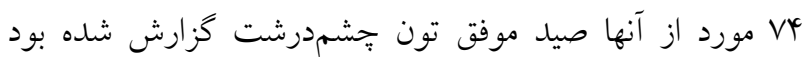
(شكل Y). ميزان صيد استحصال شده بهصورت كيلوگرم ثبت شده است. بهمنظور تعيين ميزان صيد به ازاى واحد تلاش (CPUE =Catch Per Unit Effort)، ميزان تلاش صيادى بهصورت تور ريزى موفق در مدتزمان فعاليت صيادى (بر حسب روز) محاسبه و تعيين شد. دادهاى حاصل از صيد جهانى و اقيانوس هند نيز بهترتيب از يايخاه دادهاى سازمان خوار و بار جهانى 
بومشناسى كاربردى / سال نهم / شماره جهارم / زمستان

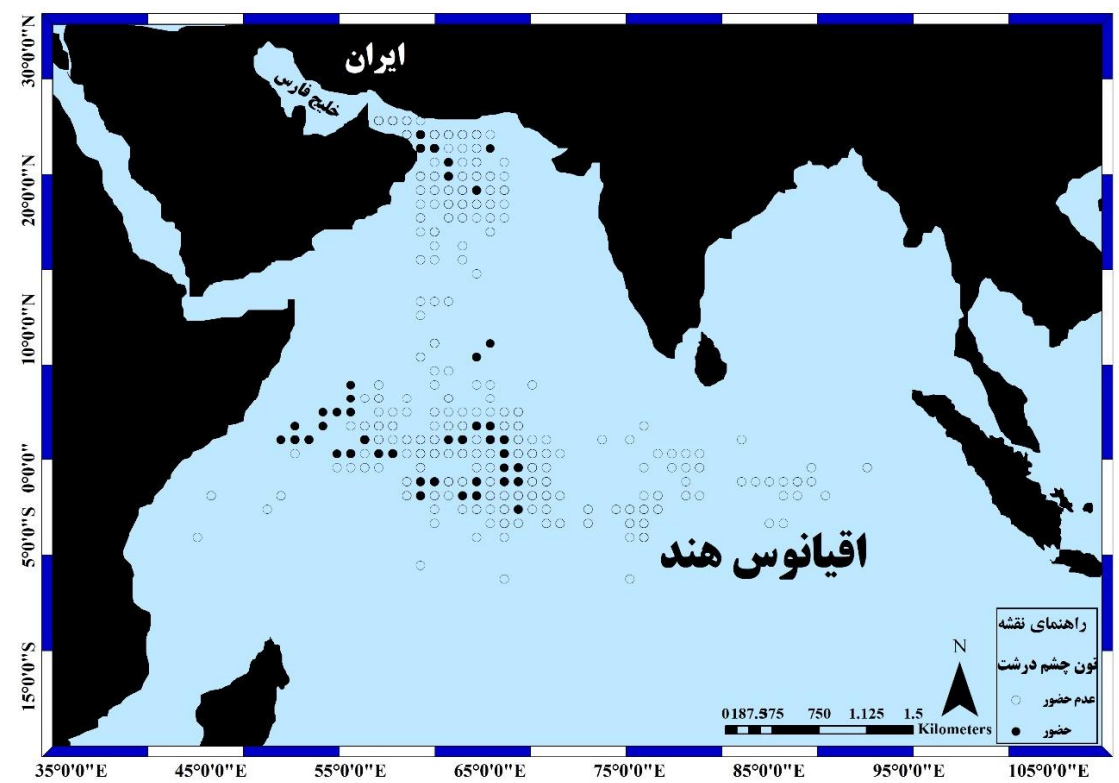

شكل r. موقعيت جغرافيايى صيد تون جشمدرشت توسط يرساينرهاى ايرانى در اقيانوس هند (نقاط حضور به معنى صيد موفق و نقاط عدم

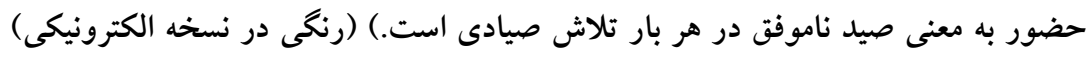
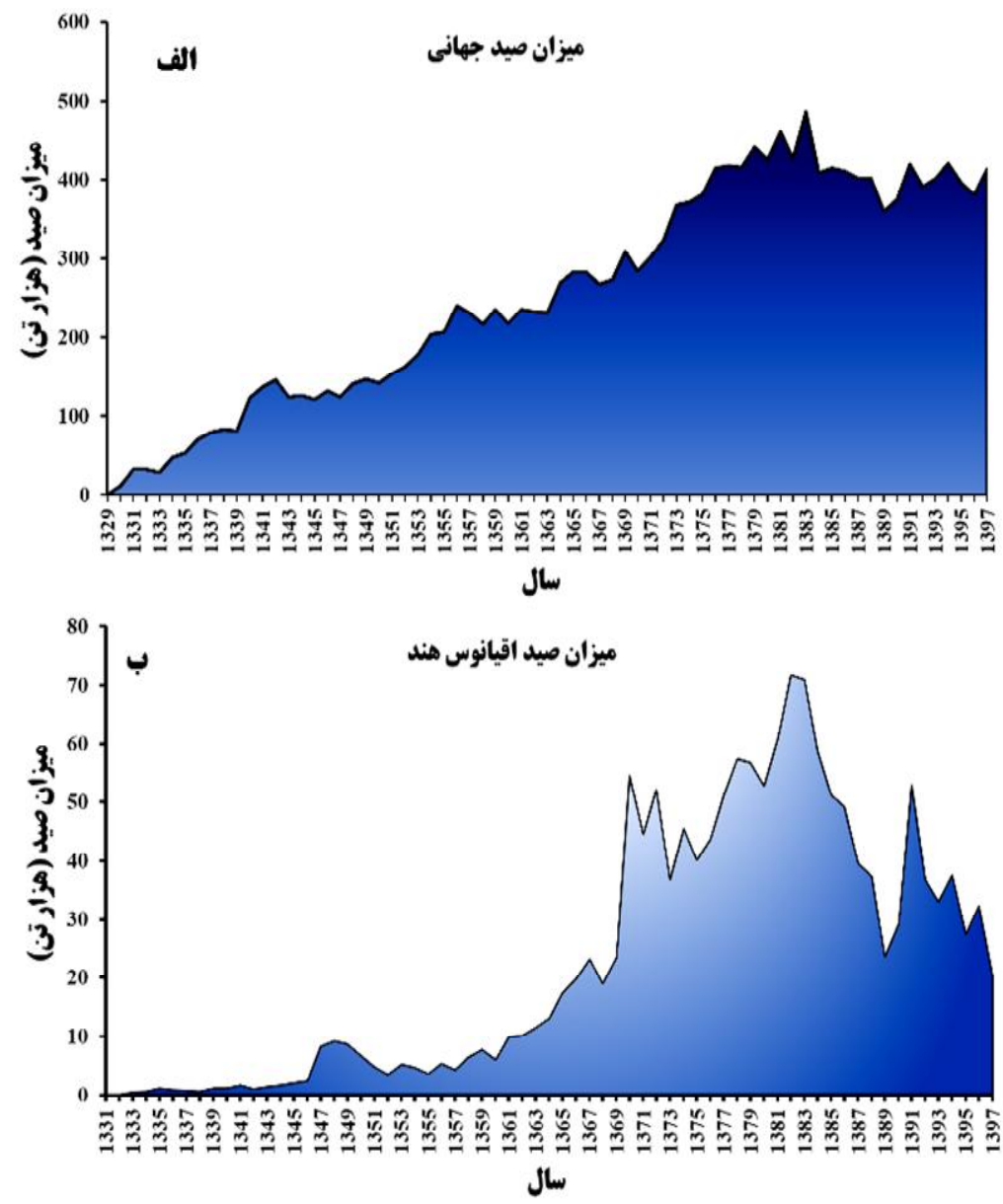

شكل r. روند بلندمدت ميزان صيد تون جشمدرشت در (الف) كل جهان و (ب) اقيانوس هند (رنخى در نسخه الكترونيكى) 
جدول ا. متغيرهاى محيطى حاصل از تصاوير ماهوارهاى مورد استفاده در بررسى صيد تون جشمدرشت

\begin{tabular}{|c|c|c|c|}
\hline منبع اخذ داده & 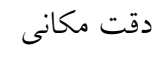 & واحد/يكا & 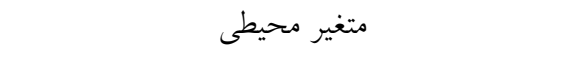 \\
\hline $\begin{array}{l}\text { https://coastwatch.pfeg.noaa.gov/erddap/griddap/er } \\
\text { dMH1 sstdmday.html }\end{array}$ & $\mu \mathrm{km} \times \mu \mathrm{km}$ & ${ }^{\circ} \mathrm{C}$ & دماى سطحى آب دريا (SST) ' \\
\hline http://www.apdrc.soest.hawaii.edu & $1^{\circ} \times 1^{\circ}$ & psu & شورى سطحى دريا (SSS) ' \\
\hline http://www.apdrc.soest.hawaii.edu & $10 \times 11^{0}$ & $\mathrm{~m}$ & عمق لايه مخلوطشونده (MLD) ع \\
\hline http://www.apdrc.soest.hawaii.edu & $1^{\circ} \times 1^{\circ}$ & $\mathrm{cm}$ & ارتفاع سطح دريا (SSH) \\
\hline $\begin{array}{l}\text { https://coastwatch.pfeg.noaa.gov/erddap/griddap/er } \\
\text { dMH1 chlamday.html }\end{array}$ & $\mathrm{r}^{\mathrm{km}} \times \mathrm{\varphi}^{\mathrm{c}} \mathrm{km}$ & $\mathrm{mg} \mathrm{m}^{-3}$ & كلروفيل سطحى آب دريا (SSC) ه \\
\hline http://www.apdrc.soest.hawaii.edu & $10 \times 11^{0}$ & $\mathrm{~cm}^{2} \mathrm{~s}^{-2}$ & انرزى جنبشى ادى (EKE) \\
\hline http://www.apdrc.soest.hawaii.edu & $1^{\circ} \times 1^{\circ}$ & $\mathrm{m}$ & عمق لايه همدمايى •r درجه سانتى گراد (D20) \\
\hline
\end{tabular}

Sea Surface $\Delta$ : Sea Surface Height $r$ : Mixed Layer Depth $r$ : Sea Surface Salinity $r$ : Sea Surface Temperature 1

Depth of $20^{\circ} \mathrm{C}$ Isotherm $\vee$ : Eddy Kinetic Energy 9 : Chlorophyll

از معيار اطلاعات آكائيك (AIC) انجام شد، بهطورى كه كمترين ميزان ارزش آكائيك (بيانگر كمترين خطا و بهترين مدل) و بالاترين درصد توضيح انحراف در مدل بهعنوان تأثير خذارترين متغيرها در نظر گرفته شد. همجنين در ادامه براى بررسى نقش متغيرهاى محيطى، ترسيم مطلوبيت زيستخاهى و بيشبينى

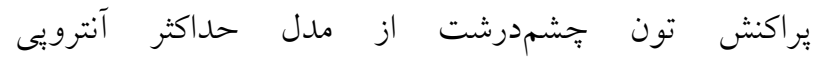
(MaxEnt, version 3.4.1) محيطى حاصل از نتايج مدل جمعى تعميميافته به منظور تخمين بهترين مناطق حضور و تعيين تأثير خذارترين متغيرها استغاده شد. اين مدل بر اساس بيشفرض ارائه شده در راهنماى مدل

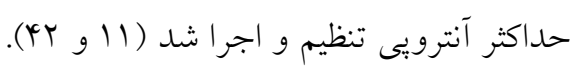

نتايج صيد تونماهيان توسط برساينرهاى ايرانى در بخش مركزى

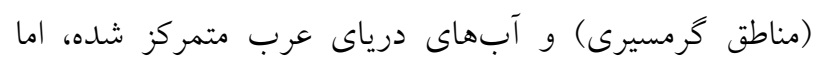
صيد تون جشمدرشت بيشتر در نواحى گرمسيرى و نيمهكرمسيرى تمركز يافته است (شكل V). نتايج حاصل از مدل جمعى تعميميافته نشان داد كه متغيرهاى زمانى (سال و ماه) و مكانى (عرض جغرافيايى) تأثير زيادى بر براكنش و ميزان صيد تون جشمدرشت داشتهاند (جدول Y). نتايج بيانكر تغييرات

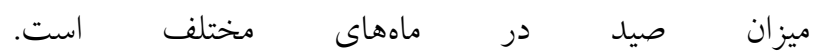

با دقت زمانى يك ماه و دقت مكانى ا درجه (با استفاده از ميانگين ارزشهاى بيكسل هاى مجاور) همسانسازى شد (جدول (1). براى بررسى و تعيين ارتباط ميزان صيد به ازاى واحد تلاش با ديا متغيرهاى مورد بررسى، مدل جمعى تعميميافته (رابطه شماره ()

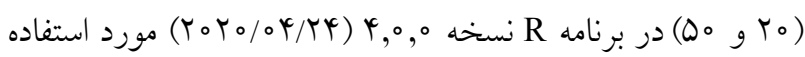
قرار گرفت. مدل جمعى تعميميافته در واقع شكل غيريارامتريك (غيرخطى) مدل جمعى خطى است. در اين مدل براى فيت كردن از ركرسيونهاى Smoothing (Fitting) ) رابطه شماره (1) (1) $g\left(\mu_{i}\right)=\mu+\sum_{j=1}^{p} f_{j}\left(\mathrm{X}_{i}\right)$

در رابطه شماره ا، حضور گونه، $\mu$ نشاندهنده عرض از مبدأ (Intercept)، Smoothing مدل توزيع كوسى مورد استفاده قرار كرفت. با توجه به بررسى دادهها و همجنين رفتار صيادى ناو گان يرساينرها، مدل جمعى تعميميافته طى دو مرحله اجرا شده و

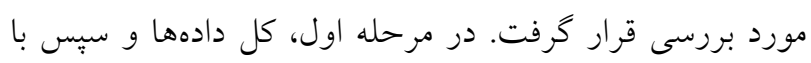
توجه به اينكه بيشترين ميزان صيد در فصل سرد (نيمه دوم سال) اتفاق افتاده بود دادههاى فصل سرد در مدل نهايى بهكار برده شد. در هر يك از مدلها برازش و انتخاب مدل با استفاده 


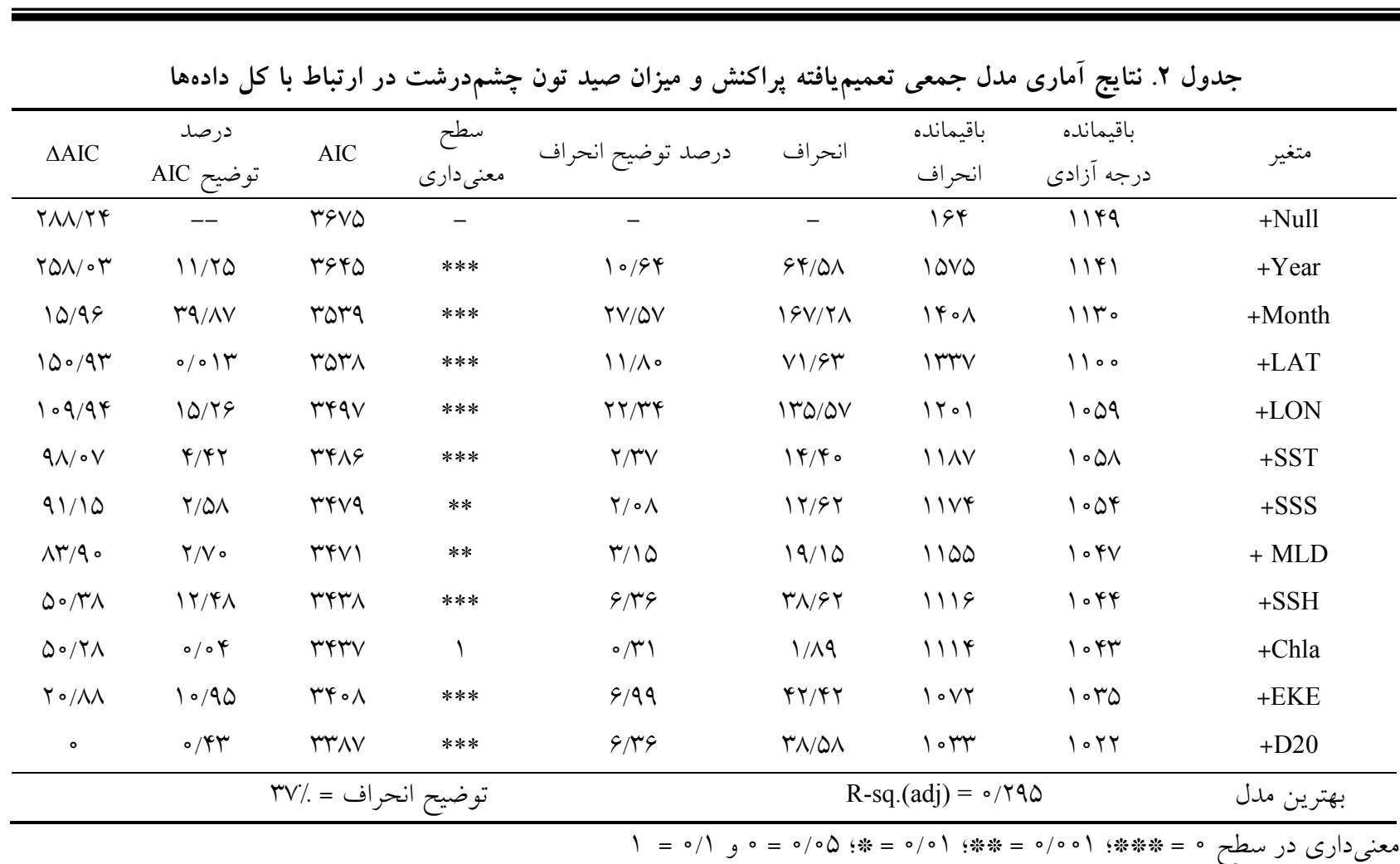

جنبشى ادى داراى تأثير مثبت بوده و عمق همدمايى مب درجه سانتى گراد در اعماق بالاتر از مبا متر اثر مطلوبى بر ميزان صيد به ازاى واحد تلاش دارد. ميانخين ماهانه متغيرهاى محيطى در نيمه دوم سال بيانكر تغييرات متغيرهاى محيطى در اقيانوس هند

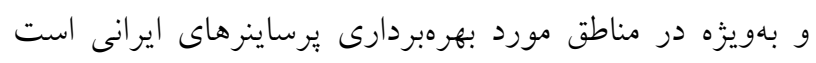
(شكل ه). درصد مشاركت (Percent contribution) و اهميت جاى گشت (Permutation importance) متغيرهاى محيطى بهكار برده شده در مدل حداكثر آنترويى بيانكر اهميت زياد متغيرهاى انرزى جنبشى ادى، كلروفيل آ و ارتفاع سطح دريا در يراكنش تون جشمدرشت در اقيانوس هند است. ميزان سطح زير منحنى (AUC =Area Under Curve) با به كارگيرى مدل حداكثر آنترويى، براى آموزش و تست مدل بهترتيب به مقدار

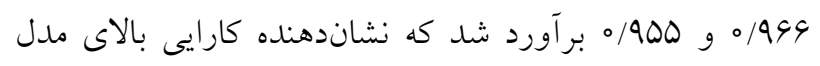
در بِيشبينى يراكنش تون جُشمدرشت است (شكل 9). نقشه مطلوبيت زيستخاهى حاصل از مدل حداكثر آنترويى در شكل ه ه نشان داده شده است. بيشترين مطلوبيت در عرضهاى ه تا ها درجه شمالى و جنوبى و بهويزه در ناحيه غربى اقيانوس هند واقع در آبهاى شرقى آفريقا (حوالى سومالى و كنيا) و طول
بيشترين ميزان صيد در ماههاى فصل سرد اتفاق افتاد. اين موضوع در مدل جمعى تعميميافته با rV/OV درصد در توضيح انحر اف و ه/AV/ درصد در توضيح آكائيك (AIC) بيانكر نقش متغير ماه (ماههاى فصل سرد) بود (جدول Y). طول جغرافيايى تأثير بهمراتب بيشترى را بر توضيح واريانس مدل نشان داد. از اينرو در مناطق غربى اقيانوس هند در حوالى مناطق شرق آفريقا ميزان حضور بيشترى اتفاق افتاده است. با بهكارگيرى دادههاى فصل سرد ميزان توضيح انحراف كل مدل از VT درصد به ه/هم درصد افزايش يافت (جداول Y و ب). در ميان متغيرهاى محيطى مورد استفاده، متغيرهاى دماى سطحى آب (SST)، ارتفاع سطح دريا (SSH)، انرزى جنبشى ادى (EKE)، و عمق هم دمايى م T درجه سانتى گراد (D20) به ترتيب بيشترين

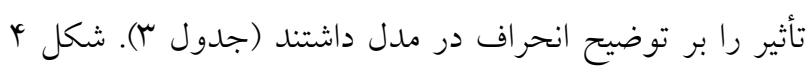

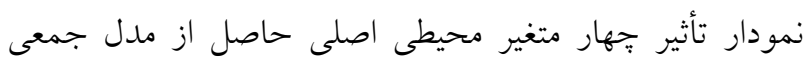
تعميميافته بر ميزان صيد تون جشمدرشت به ازاى واحد تلاش fitted GAM ) را نشان مىدهد. روند معادله مناسب مدل Pو جهار متغير اصلى نشان داد دماى مطلوب بين (function تا هب درجه سانتى گراد، مقادير مثبت ارتفاع سطح دريا و انرزى 
جدول ب. نتايج آمارى مدل جمعى تعميميافته يراكنث و صيد تون جشمدرشت در ارتباط با فصل سرد (نيمه دوم سال)

\begin{tabular}{|c|c|c|c|c|c|c|c|c|}
\hline$\Delta \mathrm{AIC}$ & 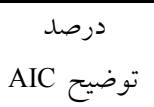 & AIC & معنى دارى سطح & درصد توضيح انحراف & انحراف & باقيمانده انحراف & درجه آزادى & متغير \\
\hline $19 V / 11$ & -- & r.IT & - & - & - & 1190 & $\Delta \Delta V$ & + Null \\
\hline $109 / 11$ & re/9T & $19 T Y$ & $* * *$ & TY/ro & $T \circ V / r Q$ & ৭४V & DYq & + Year \\
\hline$\Lambda Y / \Psi V$ & $9 / 91$ & $1 / 9 \mathrm{~V}$ & $* * *$ & $9 / 19$ & $\Delta q / \circ V$ & $9{ }_{1} \wedge$ & DFY & +Month \\
\hline $104 / 00$ & $9 / \circ \mu^{2}$ & 1919 & $* * *$ & $\Delta / \psi_{0}$ & MT/OV & 199 & DrT & $+\mathrm{LAT}$ \\
\hline $9 Q / T^{K}$ & $r / \Lambda 1$ & 1910 & $* * *$ & $\mid 9 / T 1$ & $110 / 94$ & $\vee \wedge 。$ & $4 \wedge 9$ & $+\mathrm{LON}$ \\
\hline $90 / 49$ & $|Y / T|$ & IAVG & $*$ & $11 / 44$ & $99 / 11$ & VII & $\uparrow \wedge$ & $+\mathrm{SST}$ \\
\hline$\Delta V / \Gamma \wedge$ & $1 / T V$ & IAVT & $* * *$ & $r / 99$ & 19/Tr & 990 & FVY & $+\mathrm{SSS}$ \\
\hline $04 / 94$ & $1 / 11$ & $1 \wedge \mathrm{V} 。$ & $* * *$ & $-o / \mathscr{\Psi} V$ & $-Y / \wedge Q$ & $99 \mathrm{~V}$ & FVV & + MLD \\
\hline$\mu_{\circ / D l}$ & Q/AV & 1N48 & $* *$ & V/QT & $\forall \Delta / 4 \varphi$ & $90 Y$ & 499 & $+\mathrm{SSH}$ \\
\hline$M T / M I$ & $0 / 90$ & INKV & $*$ &.$/ 11$ & $0 / 94$ & 901 & 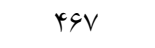 & + Chla \\
\hline $\mid r / 4 q$ & $N / \circ r$ & INTA & $* *$ & $Q / \Gamma \Lambda$ & $M T / A Y$ & 919 & rqr & $+\mathrm{EKE}$ \\
\hline$\circ$ & $0 / 11$ & 1110 & $* *$ & $4 / 94$ & $r V / 99$ & 091 & YOQ & $+\mathrm{D} 20$ \\
\hline \multicolumn{6}{|c|}{ هo/ه\% = توضيح انحراف } & R-sq. $(\operatorname{adj})=0 / \varphi_{0} 1$ & & بهترين مدل \\
\hline
\end{tabular}
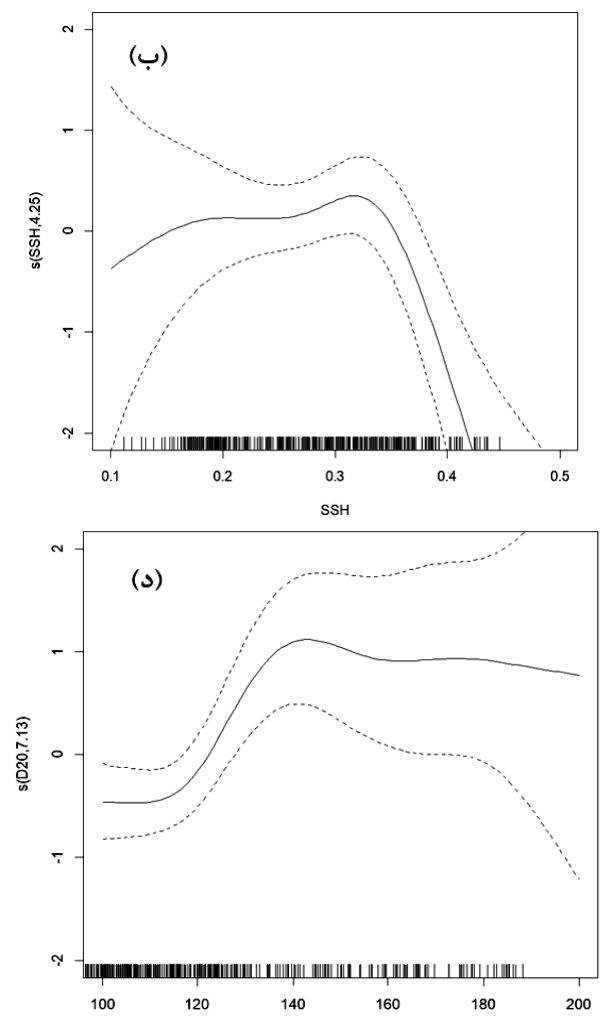

D20
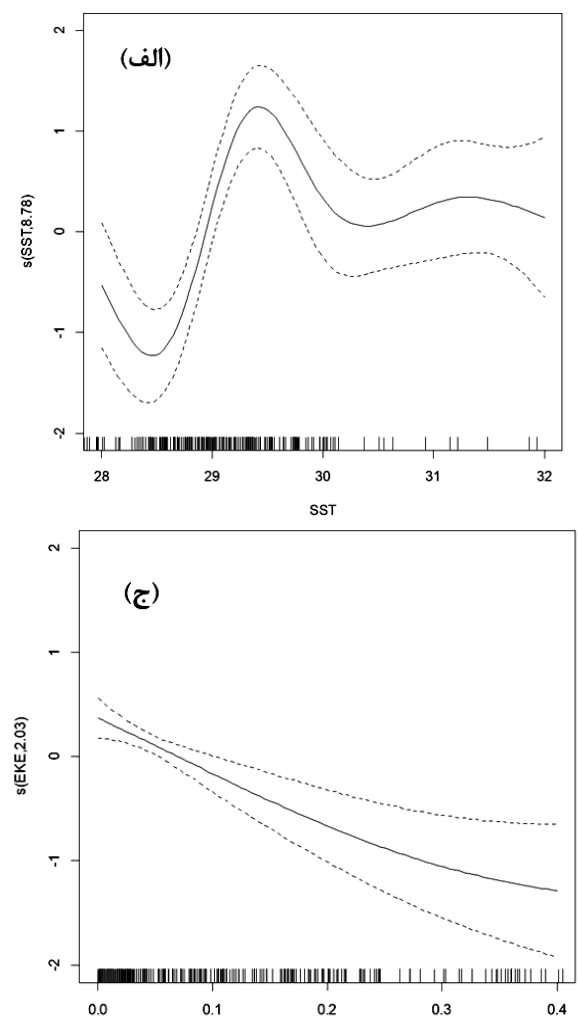

EKE

شكل \&. نمودار تأثير مهم ترين متغيرهاى محيطى (الف) دماى سطحى آب دريا، (ب) ارتفاع سطح آب دريا، (ج) انرزى جنبشى ادى

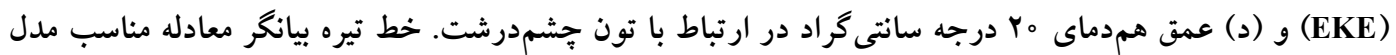

و خط نقطهجين بيانگر فاصله اطمينان هو درصد (fitted GAM function) 
بومشناسى كاربردى / سال نهم / شماره جهارم / زمستان
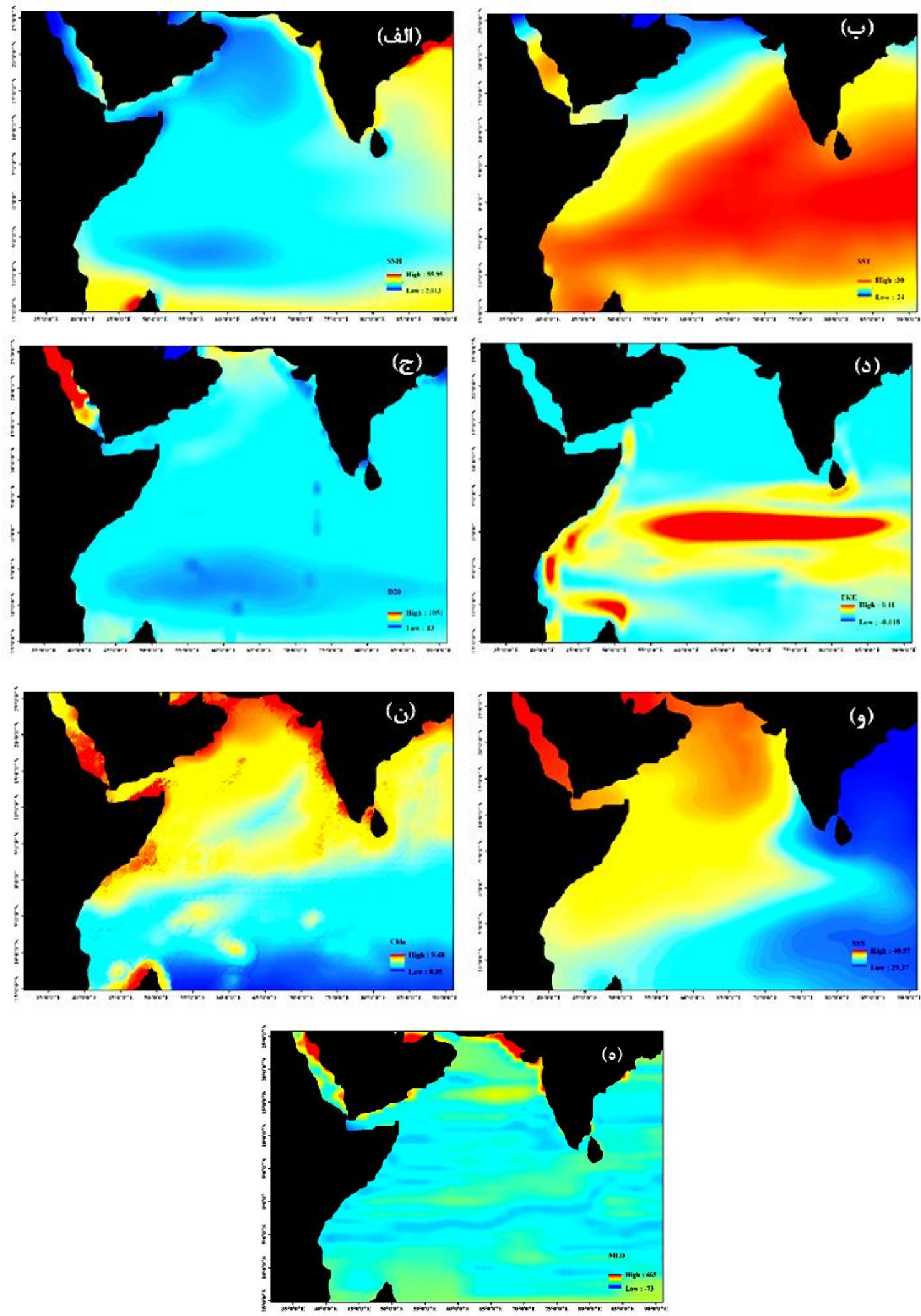

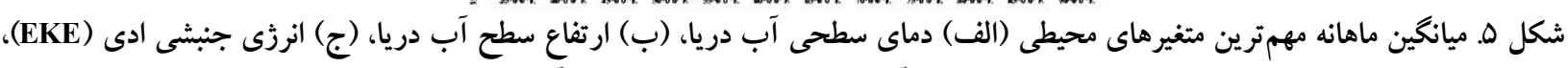

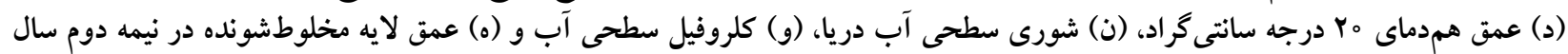
(رنخى در نسخه الكترونيكى) 


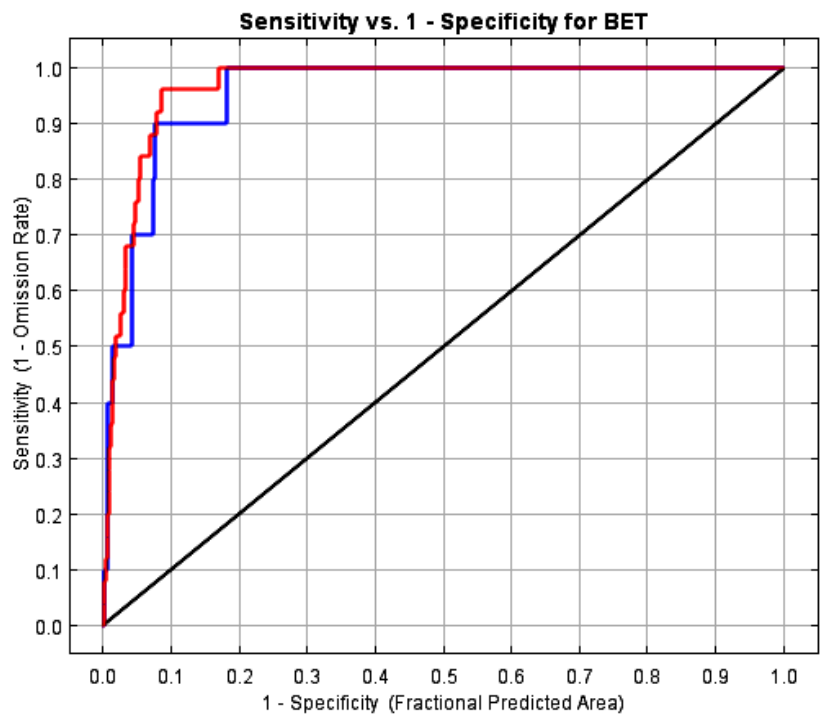

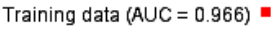

Test data (AUC $=0.955)$

Random Prediction (AUC $=0.5$ )

شكل و. سطح زير منحنى تعيينشده براى آموزش (Training data) و تست دادهها (Test data) در مدل حداكثر آنترويى (رنخى در نسخه الكترونيكى)

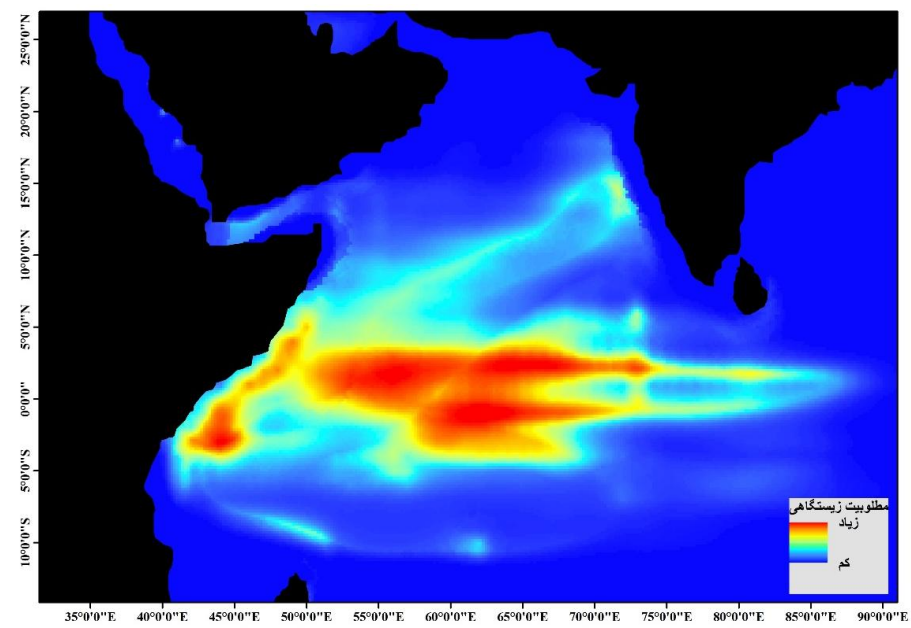

شكل V. مطلوبيت زيستخاهى تون جشمدرشت در ارتباط با متغيرهاى محيطى به كار برده شده با استفاده از مدل حداكثر آنترويى (MaxEnt) (رنخى در نسخه الكترونيكى)

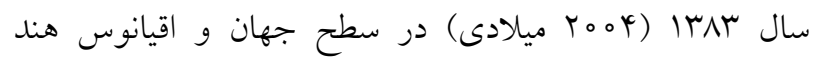

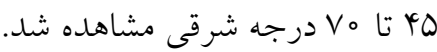
روند كاهشى را نشان مىدهد (شكل م). استحصال سطحزيان درشت با بهرهگيرى از ارتباطات تبراكنش آنها با متغيرهاى محيطى استخراجشده از تصاوير ماهوارهاى بنطور جشمشيرى

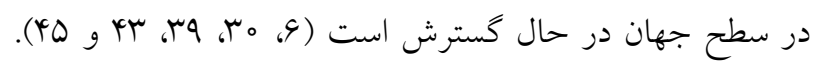
در اين مطالعه فاكتورهاى زمانى (ماه) و مكانى (طول جغرافيايى) نقش قابل ملاحظهاى در براكنش اين كونه داشت. اطلاع از متغيرهاى تأثير گذار بر يراكنش آبزيان اقتصادى و

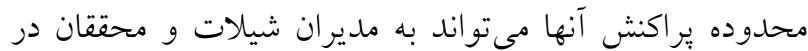

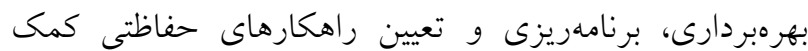
كند. صيد تون جشمدرشت بهعنوان يكى از منابع يروتئينى، از 
جدول f. درصد مشار كت (Percent contribution) و اهميت جاى جشت (Permutation importance) متغيرهاى محيطى حاصل از مدل

حداكثر آنترويى (MaxEnt)

\begin{tabular}{|c|c|c|}
\hline متغير & درصد مشاركت & اهميت جاى گشت \\
\hline EKE & $9 \circ / T$ & $\varphi / \mu$ \\
\hline Chla & $19 / 4$ & rq \\
\hline $\mathrm{SSH}$ & $11 / V$ & $r \circ / V$ \\
\hline SSS & $V / q$ & $10 / r$ \\
\hline D20 & $1 / 0$ & $\mathrm{~V} / \mathrm{V}$ \\
\hline $\mathrm{SST}$ & $1 / 0$ & $\wedge$ \\
\hline MLD & $\circ / \Lambda$ & r \\
\hline
\end{tabular}

مختلف آب در بِراكنش سطحى و عمقى تون جشمدرشت در

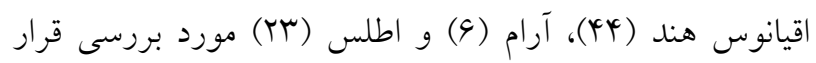

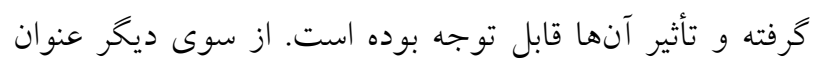

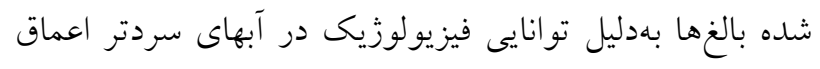

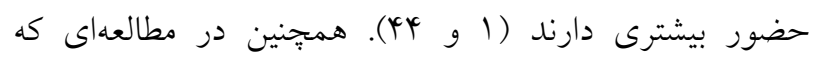

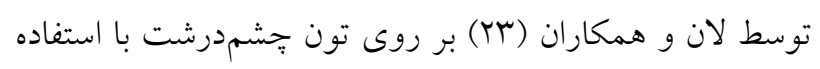

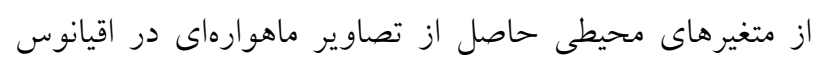

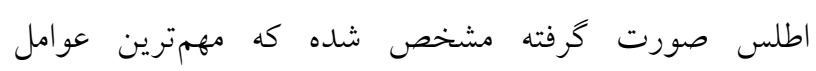

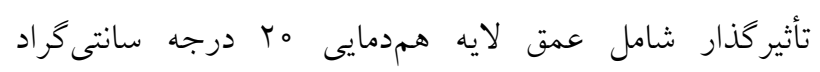

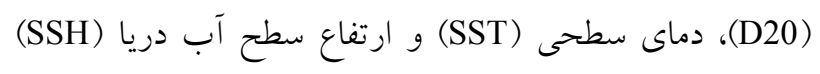

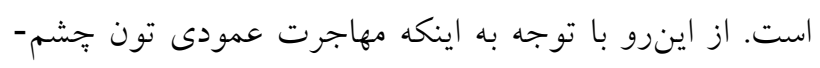

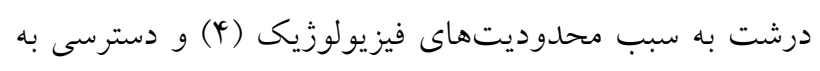

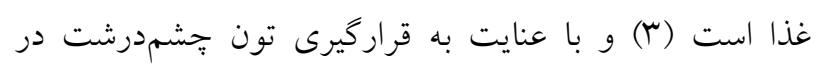
اطراف لايه ترموكلاين و اينكه D20 معرف عمق لائ لايه تشكيل

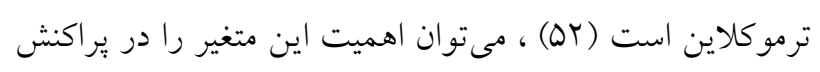

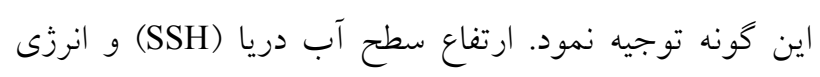

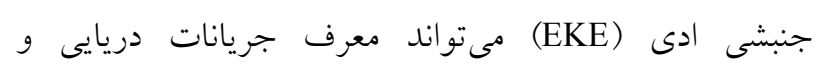
اقيانوسى باشد (Dr) كه در يراكنش عمودى و افقى تونى تونماهيان

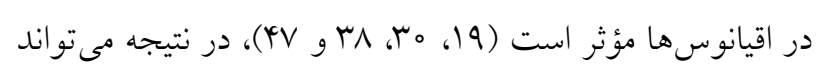

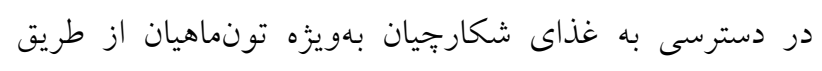

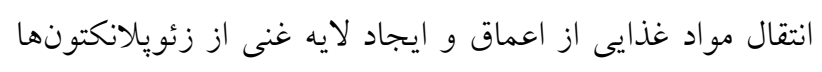

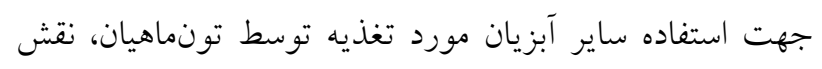

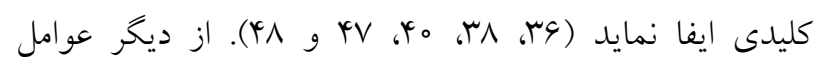

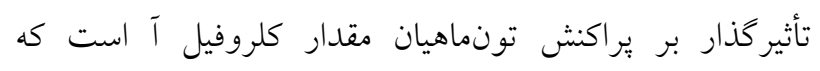

در مطالعات كذشته، فاكتورهاى زمانى و مكانى به عنوان مهم-

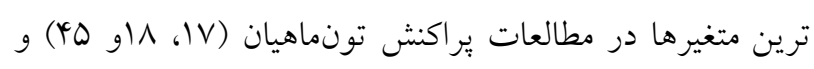

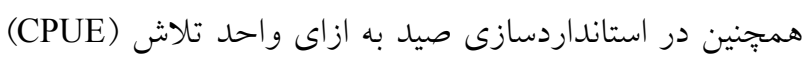

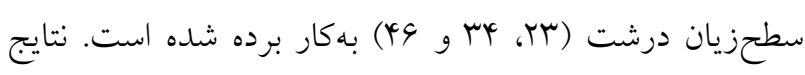

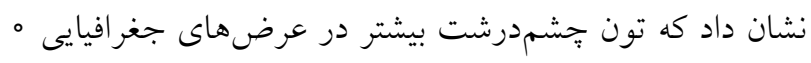

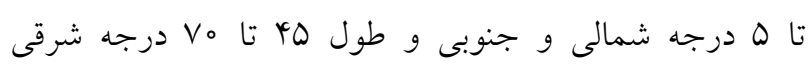

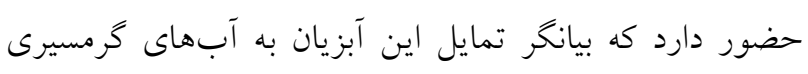
است و از اينرو كمتر به مناطق ديخر مهاجرت ميك كند. تأثير عامل ماه صيادى كه بيانكر ميزان صيد بيشتر در نيمه دوم سال

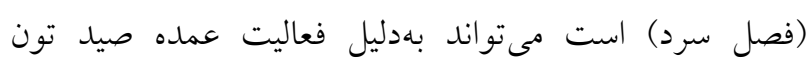

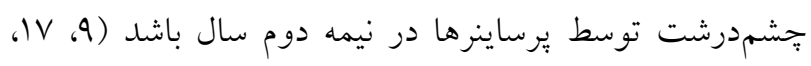

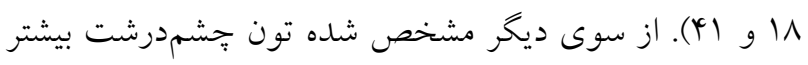

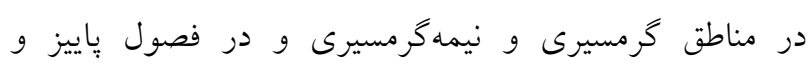

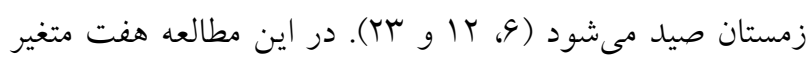

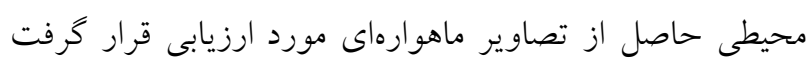

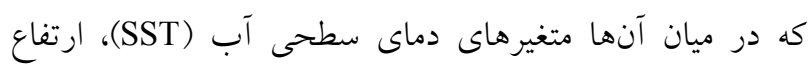

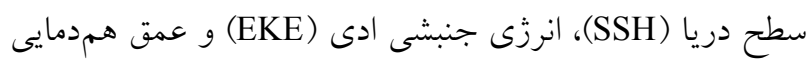

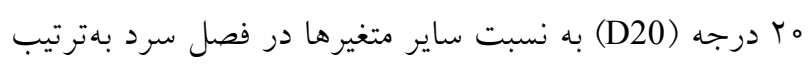

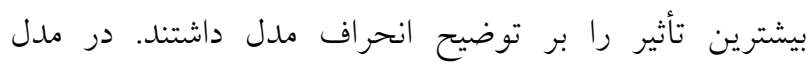

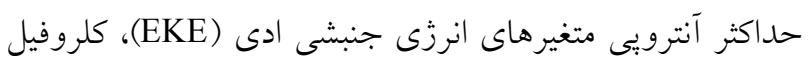

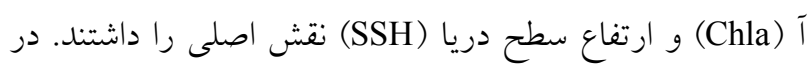
تحقيقات متعددى به نقش متغيرهاى محيطى حاصل از تصاوير

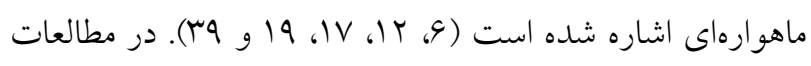
كذشته نقش درجه حرارت سطحى و درجه حرارت اعماق 


$$
\begin{aligned}
& \text { هدف (\$9) و نهايتاً اتخاذ يك رويكرد استاندارد در سياست }
\end{aligned}
$$

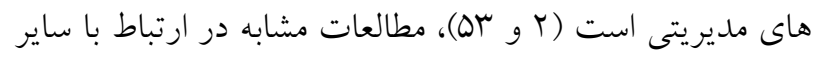

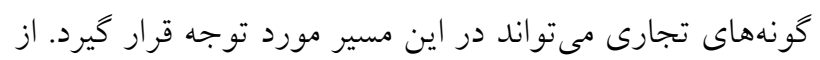

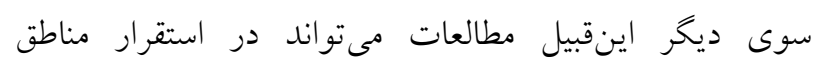

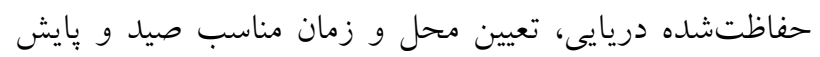

$$
\begin{aligned}
& \text { وضعيت ذخاير آبزيان به مديران شيلات كشور به به مين ميزان } \\
& \text { قابلتوجهى كمى كند. } \\
& \text { تشكر و قدردانى } \\
& \text { بدينوسيله از يزّوهشكده آرتميا و آبزى يرورى دانشخاه اروميه }
\end{aligned}
$$

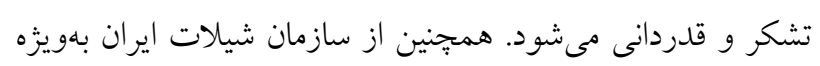

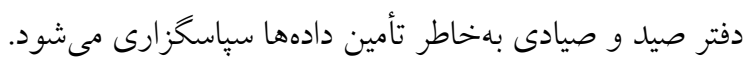

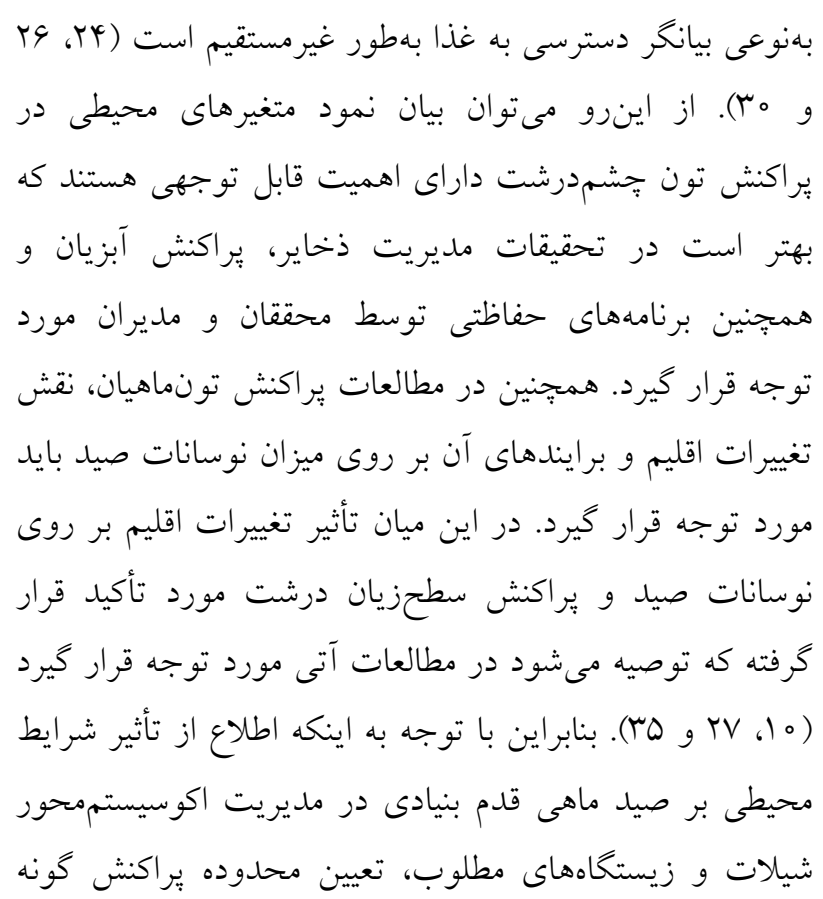$$
\text { منابع مورد استفاده }
$$

1. Arrizabalaga, H., J. G. Pereira, F. Royer, B. Galuardi, N. Goni, I. Artetxe, I. Arregi and M. Lutcavage. 2008. Bigeye tuna (Thunnus obesus) vertical movements in the Azores Islands determined with pop-up satellite archival tags. Fisheries Oceanography 17 (2): 74-83.

2. Austin, M. 2007. Species distribution models and ecological theory: A critical assessment and some possible new approaches. Ecological Modelling 200: 1-19.

3. Bertrand, A., F. X. Bard and E. Josse. 2002. Tuna food habits related to the micronekton distribution in French Polynesia. Marine Biology 140 (5): 1023-1037.

4. Brill, R. W., K. A. Bigelow, M. K. Musyl, K. A. Fritsches and E. J. Warrant. 2005. Bigeye tuna (Thunnus obesus) behavior and physiology and their relevance to stock assessments and fishery biology. Collective Volumes of Scientific Papers 57 (2): 142-161.

5. Brodziak, J. and J. Link. 2002. Ecosystem-based fishery management: what is it and how can we do it? Bulletin of Marine Science 70 (2): 589-611.

6. Cai, L. N., L. L. Xu, D. L. Tang, W. Z. Shao, Y. Liu, J. C. Zuo and Q. Y. Ji. 2020. The effects of ocean temperature gradients on bigeye tuna (Thunnus obesus) distribution in the equatorial eastern Pacific Ocean. Advances in Space Research 65 (12): 2749-2760.

7. Chiang, H. C., C. C. Hsu, G. C. C. Wu, S. K. Chang and H. Y. Yang. 2008. Population structure of bigeye tuna (Thunnus obesus) in the Indian Ocean inferred from mitochondrial DNA. Fisheries Research 90 (1-3): 305-312.

8. Dagorn, L., P. Bach and E. Josse. 2000. Movement patterns of large bigeye tuna (Thunnus obesus) in the open ocean, determined using ultrasonic telemetry. Marine Biology 136 (2): 361-371.

9. Darvishi, M., S. Y. Paighambari, A. R. Ghorbani and F. Kaymaram. 2018. Population assessment and yield per recruit of long tail tuna (Thunnus tonggol) in Northern of the Persian Gulf and Oman Sea (Iran, Hormozgan Province). Iranian Journal of Fisheries Sciences 17 (4): 776-789.

10. Dufour, F., H. Arrizabalaga, X. Irigoien and J. Santiago. 2010. Climate impacts on albacore and bluefin tunas migrations phenology and spatial distribution. Progress in Oceanography 86 (1): 283-290.

11. Elith, J., S. J. Phillips, T. Hastie, M. Dudík, Y. E. Chee and C. J. Yates. 2011. A statistical explanation of MaxEnt for ecologists. Diversity and Distributions 17 (1): 43-57.

12. Erauskin Extramiana, M., H. Arrizabalaga, A. J. Hobday, A. Cabré, L. Ibaibarriaga, I. Arregui, H. Murua and G. Chust. 2019. Large-scale distribution of tuna species in a warming ocean. Global Change Biology 25 (6): 20432060.

13. Evans, K., A. Langley, N. P. Clear, P. Williams, T. Patterson, J. Sibert, J. Hampton and J. S. Gunn. 2008. Behaviour 
and habitat preferences of bigeye tuna (Thunnus obesus) and their influence on longline fishery catches in the western Coral Sea. Canadian Journal of Fisheries and Aquatic Sciences 65 (11): 2427-2443.

14. Haghi Vayghan, A., H. Poorbagher, H. Taheri Shahraiyni, H. Fazli and H. Nasrollahzadeh Saravi. 2013. Suitability indices and habitat suitability index model of Caspian kutum (Rutilus frisii kutum) in the southern Caspian Sea. Aquatic Ecology 47 (4): 441-451.

15. Haghi Vayghan, A., H. Fazli, R. Ghorbani, M. A. Lee and H. N. Saravi. 2015. Temporal habitat suitability modeling of Caspian shad (Alosa spp.) in the southern Caspian Sea. Journal of Limnology 75 (1): 210-223.

16. Haghi Vayghan, A., R. Zarkami, R. Sadeghi and H. Fazli. 2016. Modeling habitat preferences of Caspian kutum, Rutilus frisii kutum (Kamensky, 1901)(Actinopterygii, Cypriniformes) in the Caspian Sea. Hydrobiologia 766 (1): 103-119.

17. Haghi Vayghan, A., R. Ghorbani, S. Y. Peyghambari, M. A. Lee, D. M. Kaplan and B. A. Block. 2017. Relationship between yellowfin tuna (Thunnus albacares) distribution caught by Iranian purse seiners and environmental variables in the Indian Ocean. Iranian Scientific Fisheries Journal 26 (1): 67-82.

18. Haghi Vayghan, A., R. Ghorbani, Y. Peighambari, M. A. Lee, D. M. Kaplan and B. A. Block. 2018. Association between Skipjack (Katsuwonus pelamis) distribution caught by Iranian purse seiners and environmental variables in the Indian Ocean. Journal of Applied Ichthyological Research 6 (1): 1-20.

19. Haghi Vayghan, A., M. A. Lee, J. S. Weng, S. Mondal, C. T. Lin and Y. C. Wang. 2020. Multisatellite-based feeding habitat suitability modeling of Albacore Tuna in the Southern Atlantic Ocean. Remote Sensing 12 (16): 2515 .

20. Hastie, T. and R. Tibshirani. 1990. Generalized additive models. Chapman and Hall, London.

21. Hilborn, R. 2011. Future directions in ecosystem based fisheries management: A personal perspective. Fisheries Research 108: 235-239.

22. Lam, C. H., B. Galuardi and M. E. Lutcavage. 2014. Movements and oceanographic associations of bigeye tuna (Thunnus obesus ) in the Northwest Atlantic. Canadian Journal of Fisheries and Aquatic Sciences 71 (10): 15291543.

23. Lan, K. W., M. A. Lee, C. P. Chou and A. H. Vayghan. 2018. Association between the interannual variation in the oceanic environment and catch rates of bigeye tuna (Thunnus obesus) in the Atlantic Ocean. Fisheries Oceanography 27 (5): 395-407.

24. Lan, K. W., T. Nishida, M. A. Lee, H. J. Lu, H. W. Huang, S. K. Chang and Y. C. Lan. 2012. Influence of the marine environment variability on the yellowfin tuna (Thunnus albacares) catch rate by the Taiwanese longline fishery in the Arabian Sea, with special reference to the high catch in 2004. Journal of Marine Science and Technology 20 (5): 514-524.

25. Lan, K. W., M. A. Lee, H. J. Lu, W. J. Shieh, W. K. Lin and S. C. Kao. 2011. Ocean variations associated with fishing conditions for yellowfin tuna (Thunnus albacares) in the equatorial Atlantic Ocean. ICES Journal of Marine Science: Journal Du Conseil 68 (6): 1063-1071.

26. Lan, K. W., T. Shimada, M. A. Lee, N. J. Su and Y. Chang. 2017. Using remote-sensing environmental and fishery data to map potential Yellowfin Tuna habitats in the Tropical Pacific Ocean. Remote Sensing 9 (5): 444.

27. Last, P. R., W. T. White, D. C. Gledhill, A. J. Hobday, R. Brown, G. J. Edgar and G. Pecl. 2011. Long-term shifts in abundance and distribution of a temperate fish fauna: a response to climate change and fishing practices. Global Ecology and Biogeography 20 (1): 58-72.

28. Lee, P. F., I. C. Chen and W. N. Tzeng. 2005. Spatial and temporal distribution patterns of bigeye tuna (Thunnus obesus) in the Indian Ocean. ZOOLOGICAL STUDIES-TAIPEI 44 (2): 260.

29. Lee, M. A., A. H. Vayghan, D. C. Liu and W. C. Yang. 2017. Potential and prospective seasonal distribution of hotspot habitat of albacore tuna (thunnus alalunga) in the South Indian Ocean using the satellite data. In: 2017 IEEE International Geoscience and Remote Sensing Symposium (IGARSS). Fort Worth, Texas, USA. pp. 5747-5750.

30. Lee, M. A., J. S. Weng, K. W. Lan, A. H. Vayghan, Y. C. Wang and J. W. Chan. 2020. Empirical habitat suitability model for immature albacore tuna in the North Pacific Ocean obtained using multisatellite remote sensing data. International Journal of Remote Sensing 41 (15): 5819-5837.

31. Liming, S., X. Liuxiong and C. Xinjun. 2004. Relationship between bigeye tuna vertical distribution and the temperature,salinity in the Central Atlantic Ocean. Journal of Fishery Sciences of China 11 (6): 561-566.

32. Lumban-Gaol, J., R. R. Leben, S. Vignudelli, K. Mahapatra, Y. Okada, B. Nababan, M. Mei-Ling, K. Amri, R. E. Arhatin and M. Syahdan. 2015. Variability of satellite-derived sea surface height anomaly, and its relationship with Bigeye tuna (Thunnus obesus) catch in the Eastern Indian Ocean. European Journal of Remote Sensing 48: 465-477.

33. Matsumoto, T., T. Kitagawa and S. Kimura. 2013. Vertical behavior of bigeye tuna (Thunnus obesus) in the northwestern Pacific Ocean based on archival tag data. Fisheries Oceanography 22 (3): 234-246.

34. Maunder, M. N. and A. E. Punt. 2004. Standardizing catch and effort data: a review of recent approaches. Fisheries Research 70 (2-3 SPEC. ISS.): 141-159. 
35. Merino, G., H. Arrizabalaga, I. Arregui, J. Santiago, H. Murua, A. Urtizberea, E. Andonegi, P. De Bruyn and L. T. Kell. 2019. Adaptation of North Atlantic Albacore fishery to climate change: yet another potential benefit of harvest control rules. Frontiers in Marine Science 6 (620).

36. Mugo, R., S. I. Saitoh, A. Nihira and T. Kuroyama. 2010. Habitat characteristics of skipjack tuna (Katsuwonus pelamis) in the western North Pacific: a remote sensing perspective. Fisheries Oceanography 19 (5): $382-396$.

37. Musyl, M. K., R. W. Brill, C. H. Boggs, D. S. Curran, T. K. Kazama and M. P. Seki. 2003. Vertical movements of bigeye tuna (Thunnus obesus) associated with islands, buoys, and seamounts near the main Hawaiian Islands from archival tagging data. Fisheries Oceanography 12 (3): 152-169.

38. Nieto, K., Y. Xu, S. L. H. Teo, S. McClatchie and J. Holmes. 2017. How important are coastal fronts to albacore tuna (Thunnus alalunga) habitat in the Northeast Pacific Ocean? Progress in Oceanography 150: 62-71.

39. Nimit, K., N. K. Masuluri, A. M. Berger, R. P. Bright, S. Prakash, U. TVS, S. K. T. P. Rohit, T. A. S. Ghosh and S. P. Varghese. 2020. Oceanographic preferences of yellowfin tuna (Thunnus albacares) in warm stratified oceans: a remote sensing approach. International Journal of Remote Sensing 41 (15): 5785-5805.

40. Olson, D. B., G. L. Hitchcock, A. J. Mariano, C. J. Ashjian, G. Peng, R.W. Nero and G. P. Podestá 1994. Life on the edge: marine life and fronts. Oceanography 7 (2): 52-60.

41. Parsa, M., E. Kamrani, M. Safaei, S. Y. Paighambari and T. Nishida. 2017. Length frequency, length-weight relationship and catch per unit of effort (CPUE) of Longtail tuna (Thunnus tonggol) and Yellowfin tuna (Thunnus albacares) caught by purse seine in Oman Sea. Journal of Aquatic Ecology 7 (2): 19-29.

42. Phillips, S. J., R. P. Anderson and R.E . Schapire. 2006. Maximum entropy modeling of species geographic distributions. Ecological Modelling 190: 231-259.

43. Sculley, M. L. and J. Brodziak. 2020. Quantifying the distribution of swordfish (Xiphias gladius) density in the Hawaii-based longline fishery. Fisheries Research 230: 105638.

44. Song, L., J. Zhou, Y. Zhou, T. Nishida, W. Jiang and J. Wang. 2009. Environmental preferences of bigeye tuna, Thunnus obesus, in the Indian Ocean: an application to a longline fishery. Environmental Biology of Fishes 85 (2): 153-171.

45. Su, N. J., C. H. Chang, Y. T. Hu, W. C. Chiang and C. T. Tseng. 2020. Modeling the spatial distribution of Swordfish (Xiphias gladius) using fishery and remote sensing data: approach and resolution. Remote Sensing 12 (6): 947.

46. Su, N. J., S. Z. Yeh, C. L. Sun, A. E. Punt, Y. Chen and S. P. Wang. 2008. Standardizing catch and effort data of the Taiwanese distant-water longline fishery in the western and central Pacific Ocean for bigeye tuna, Thunnus obesus. Fisheries Research 90 (1-3): 235-246.

47. Syamsuddin, M., S. I. Saitoh, T. Hirawake, F. Syamsudin and M. Zainuddin. 2016. Interannual variation of bigeye tuna (Thunnus obesus) hotspots in the eastern Indian Ocean off Java. International Journal of Remote Sensing 37 (9): 2087-2100.

48. Teo, S. L. H., A. M. Boustany and B. A. Block. 2007. Oceanographic preferences of Atlantic bluefin tuna, Thunnus thynnus, on their Gulf of Mexico breeding grounds. Marine Biology 152 (5): 1105-1119.

49. Thrush, S. F. and P. K. Dayton. 2010. What can ecology contribute to ecosystem-based management? Annual Review of Marine Science 2 (1): 419-441.

50. Wood, S. N. 2006. Generalized Additive Models: an Introduction with R. CRC Press: Boca Raton, FL.

51. Yang, S., J. Ma, Y. Wu, X. Fan, S. Jin and X. Chen. 2015. Relationship between temporal-spatial distribution of fishing grounds of bigeye tuna (Thunnus obesus) and thermocline characteristics in the Atlantic Ocean. Acta Ecologica Sinica 35 (3): 1-9.

52. Yu, L. 2003. Variability of the depth of the $20^{\circ} \mathrm{C}$ isotherm along $6^{\circ} \mathrm{N}$ in the Bay of Bengal: Its response to remote and local forcing and its relation to satellite SSH variability. Deep-Sea Research Part II: Topical Studies in Oceanography 50 (12-13): 2285-2304.

53. Zhang, P., L. Yang, X. F. Zhang, and Y. G. Tang. 2010. The present status and prospect on exploitation of tuna and squid fishery resources in South China Sea. South China Fisheries Science 6 (1): 68-74. 


\title{
Distribution Modeling of Bigeye Tuna (Thunnus obesus Lowe, 1839), Using Satellite Derived Environmental Variables in Indian Ocean
}

\author{
A. Haghi Vayghan ${ }^{1 *}$ \\ (Received: September 20-2020; Accepted: November 10-2020)
}

\begin{abstract}
Understanding effects of environment on the distribution of economic fish is a fundamental step in the ecosystem-based management and ultimately a standard approach in management policies. Bigeye tuna (Thunnus obesus) is one of the most important aquatic species harvested in the Indian Ocean. The present study investigated the association of different variables effecting the rate of catch and distribution of bigeye tune, using generalized additive model (GAM) and maximum entropy (MaxEnt) and satellite derived environmental variables in the Indian Ocean. Results highlighted the importance of temporal and spatial variables along with the eddy kinetic energy, sea level height, depth of $20^{\circ} \mathrm{C}$ isotherm and sea surface temperature on the distribution of the species. The most suitable habitat predicted by MaxEnt model was observed around the latitudes of 0 to 5 degrees of north and south, mainly in the western part of the Indian Ocean and longitude of 45 to 70 degrees east. Using satellite data, the present study determinied the important factors and suitable habitats for the species, which can be useful for Iranian fisheries managers to increase the fishing efficiency and implementing of ecosystem-based fisheries management in the shared exploited stocks of the Indian Ocean.
\end{abstract}

Keywords: Bigeye tuna, distribution, habitat modeling, ecosystem management

1. Department of Ecology \& Aquatic stocks management, Artemia \& Aquaculture Research Institute, Urmia University, Urmia, Iran.

*: Corresponding Author, Email: a.haghi@urmia.ac.ir 